\title{
FEDERALISMO Y ENDEUDAMIENTO PÚBLICO DE ESTADOS Y MUNICIPIOS EN MÉXICO
}

\author{
FEDERALISM AND PUBLIC DEBT OF THE STATES AND \\ MUNICIPALITIES IN MEXICO
}

\author{
María Isabel García Morales ${ }^{(*)}$ \\ Instituto Politécnico Nacional, México (DF), México. \\ Horácio Sánchez Bárcenas ${ }^{(*)}$ \\ Instituto Politécnico Nacional, México (DF), México.
}

Resumen: El objetivo de este trabajo es explicar las causas y algunas implicaciones del endeudamiento de los estados y municipios, además de su importancia y evolución durante el sexenio de 2006-2012, se hace énfasis en los estados más endeudados. Esta problemática se aborda en el marco del Sistema Nacional de Coordinación Fiscal que es el que regula las relaciones financieras entre los tres órdenes de gobierno en México. Se retoma parte del debate nacional que se da en el Congreso de la Unión para regular dicho endeudamiento.

Palabras claves: deuda pública; transferencias federales; gobiernos subnacionales; participaciones, coordinación fiscal.

Abstract: The purpose of this job is to explain the causes and some implications of the debt of the states and municipalities, as well as its importance and evolution during the government period from 2006 to 2012, this job emphasizes the most indebted states. This problem is addressed in the framework of the "Sistema Nacional de Coordinación Fiscal" who regulates the finance relationships between the three level of government in Mexico. It takes part of the national debate that occurs in the "Congreso de la Unión" to regulate the mentioned indebtedness.

Key words: Public debt; Federal transfers; Sub-national governments; Participations and tax coordination.

(*) Doctora, Profesora de la Sección de Estudios de Posgrado e Investigación de la Escuela Superior de Economía del Instituto Politécnico Nacional, Ciudad de México, México. E-mail: <isabel_garciam@yahoo.com.mx>.

(**) Maestro, Profesor del Departamento de Economía Política de la Escuela Superior de Economía del Instituto Politécnico Nacional, Ciudad de México, México. E-mail: <hosanba@hotmail.com>. Recebido en: 31.10.2013, aceptado en: 05.12 .2013 


\section{INTRODUCCIÓN}

La historia de América Latina a partir de la independencia se ha caracterizado por una gran centralización de las decisiones políticas y económicas. Los recursos públicos nunca han sido suficientes para cubrir las tareas, responsabilidades y funciones del sector público.

En México ante los bajos ingresos tributarios de los gobiernos locales, la alta dependencia de las transferencias federales, la caída de la recaudación con la crisis de 2009 y laxa regulación para contratar deuda pública, se ha observado el aumento del endeudamiento público, tanto de los estados como municipios, del 2006 al 2012, sobre todo en 2009.

Este trabajo tiene la finalidad de explicar el problema del endeudamiento de los gobiernos subnacionales en el contexto del Sistema Nacional de Coordinación Fiscal, por ello abordaremos de manera general el funcionamiento del Sistema Nacional de Coordinación Fiscal (SNCF) en el entorno federalista mexicano que rige al menos en términos legales. Consideramos que es importante que se conozca como son las relaciones fiscales entre el gobierno federal con los estados, qué tipo de transferencias federales hace el gobierno federal a los estados y municipios, y finalmente, lo más importante, ¿Cuál es la relación entre las transferencias federales a los estados y municipios con su endeudamiento público?

Este estudio se hace con información de la Secretaria de Hacienda y Crédito Público (SHyCP), institución mexicana encargada de registrar de manera oficial el endeudamiento público de los estados y municipios. El análisis se centra en los estados con mayores montos de deuda pública.

Al ser este trabajo producto del proyecto de investigación "Endeudamiento público de los estados y municipios en México, 2006-2012", se agradece el apoyo al Instituto Politécnico Nacional.

\section{EL FEDERALISMO FISCAL EN MÉXICO Y SISTEMA NACIONAL DE COORDINACIÓN FISCAL MEXICANO}

Para abordar el problema del endeudamiento de los estados y municipios, es preciso explicar de manera muy general como funciona el Federalismo Fiscal Mexicano, y por tanto, que es el Sistema Nacional de Coordinación Fiscal (SNCF).

Posterior a la Independencia (1810) prevaleció en México un desorden fiscal que produjo duplicidad de impuestos sobre la misma fuente. Después de la Revolución Mexicana (1910), mediante convenciones fiscales (1925, 1933 y 1947), se trataron los problemas de concurrencia y coordinación fiscal. Con la Ley de Coordinación Fiscal (LCF) de 1953 se intentaron esquemas de coordinación (TELLO, 2004).

En 1980 se reformó la LCF, se crea el Sistema Nacional de Coordinación Fiscal (SNCF), se derogan un gran número de impuestos federales al consumo y se implanta el 
Impuesto al Valor Agregado (IVA) ${ }^{(1)}$, se entrega su administración a las entidades, pero en 1990 se les retira y regresa al gobierno federal (PÉREZ TORRES, 1997). Durante el gobierno de Ernesto Zedillo Ponce de León (1994-2000) se reformó el SNCF, dio prioridad a la descentralización del gasto federal (vía aportaciones), más no así a las potestades tributarias de cada orden de gobierno, es decir, a la descentralización del ingreso.

Ley de Coordinación Fiscal (LCF) regula el Sistema Nacional de Coordinación Fiscal (SNCF) tiene por objeto coordinar el sistema fiscal con los estados, Distrito Federal y municipios, establecer la participación que corresponda a sus haciendas públicas en los ingresos federales, distribuir entre ellos dichas participaciones; fijar reglas de colaboración administrativa entre las diversas autoridades fiscales; constituir los órganos en materia de coordinación fiscal y dar las bases de su organización y funcionamiento.

La integración de los estados al SNCF implicó que estos dejarían de ejercer la mayoría de sus potestades tributarias a cambio de participar de los ingresos federales, anulándose con ello su soberanía fiscal. De manera, que el estado adherido percibiría parte de la recaudación de las contribuciones federales, pero sin mantener contribuciones propias (PÉREZ TORRES, 1997).

José María Calderón Rodríguez señala que en términos políticos significó ceder la soberanía estatal y con ello un atraso en términos democráticos, debido a la centralización fiscal, ya que los Estados al adherirse al SNCF, asumían el compromiso de no gravar, a cambio de obtener recursos de las participaciones federales (CALDERÓN, 1998).

José María Calderón menciona que en términos fiscales se incrementó la eficiencia recaudatoria, se eliminó la concurrencia impositiva y doble tributación (CALDERÓN, 1998). Actualmente, los contribuyentes acuden a una autoridad fiscal, los gravámenes tienen una política fiscal uniforme en todo el país.

El propósito de simplificar el SNCF para los contribuyentes se logró, pero a costa de que los estados perdieran su soberanía fiscal, quedando imposibilitados para exigir más potestades fiscales (PÉREZ TORRES, 1997), ante esta situación algunos estados han recurrido al endeudamiento público.

Con el SNCF, las entidades y municipios han incrementado sus ingresos a través de su participación en los distintos impuestos federales (participaciones) y fondos presupuestales (aportaciones); sin embargo, se ha generado una dependencia casi absoluta de sus haciendas respecto de las transferencias de recursos federales. Esta situación no contribuye al fortalecimiento institucional de dichos órdenes de gobierno. Esto ha provocado que la generación de ingresos propios de los estados sea en promedio entorno al $7 \%$ de sus ingresos totales, la manera más cómoda de obtener recursos es a través del financiamiento, es decir, endeudamiento público.

(1) El rediseño global de la imposición indirecta (mediante el IVA) hizo posible la eliminación de 31 impuestos, especiales, federales y el impuesto del timbre. Fue posible eliminar la concurrencia fiscal ya que los Estados coordinados no podían cobrar impuestos (CALDERÓN, 1998). 


\subsection{FORMA DE DISTRIBUCIÓN DE LOS RECURSOS FISCALES}

La Ley de Coordinación Fiscal (LCF) contempla básicamente dos formas de distribución de recursos federales: las participaciones que provienen de la Recaudación Federal Participable (ramo 28); y las aportaciones del ramo 33 del Presupuesto de Egresos de la Federación.

Las participaciones son transferencias no condicionadas. Tienen la finalidad de compartir la recaudación de los impuestos federales con los estados y los municipios.

Ha aumentado el monto de las participaciones que reciben los estados y municipios, pero su excesiva proporción frente a los ingresos propios ha provocado poca capacidad tributaria y una gran dependencia financiera (PÉREZ TORRES, 1997) y sin duda, el incremento de su endeudamiento público.

Además de las participaciones y con independencia de ellas, el gobierno federal transfiere a los estados, Distrito Federal, municipios y delegaciones, recursos denominados aportaciones, a través de 8 fondos:

I. Fondo de Aportaciones para la Educación Básica y normal (FAEB). Distribuido a estados y Distrito Federal, conforme a la Ley General de Educación. Este fondo será sustituido en 2015 por el Fondo de Aportaciones para la Nómina Educativa;

II. Fondo de Aportaciones para los Servicios de Salud (FASSA). A estados y Distrito Federal, en base a la Ley General de Salud. Los fondos de educación (FAEB) y salud (FASSA) abarcan casi $3 / 4$ partes del total de los ocho fondos;

III. Fondo de Aportaciones para la Infraestructura Social (FAIS). A estados y municipios;

IV. Fondo de Aportaciones para el Fortalecimiento de los Municipios y de las Demarcaciones del DF (FORTAMUNDF). A municipios y delegaciones del DF;

V. Fondo de Aportaciones Múltiples (FAM), a estados y Distrito Federal. Se destina a desayunos escolares, apoyos alimentarios, y de asistencia social a la población;

VI. Fondo de Aportaciones para la Educación Tecnológica y de Adultos (FAETA). Se transfiere a estados y Distrito Federal;

VII. Fondo de Aportaciones para la Seguridad Pública de los Estados y del Distrito Federal (FASP). A estados y DF;

VIII. Fondo de Aportaciones para el Fortalecimiento de Entidades Federativas (FEF). Distribuido a los estados.

\subsection{INGRESOS DE LOS GOBIERNOS ESTATALES EN MÉXICO}

Los estados y municipios en México tienen una alta dependencia financiera de las transferencias federales (participaciones y aportaciones), en promedio éstas significaron en 2011 el $80.2 \%$ de sus ingresos totales. 
Los estados generan muy pocos ingresos propios, como se aprecia en la figura 1 , éstos son del $7.2 \%$ de los ingresos totales, los impuestos apenas representan el 3.1\% y los ingresos no tributarios el $4.1 \%$, mientras que los ingresos por financiamiento son mayores a los ingresos propios.

\section{Quadro 1}

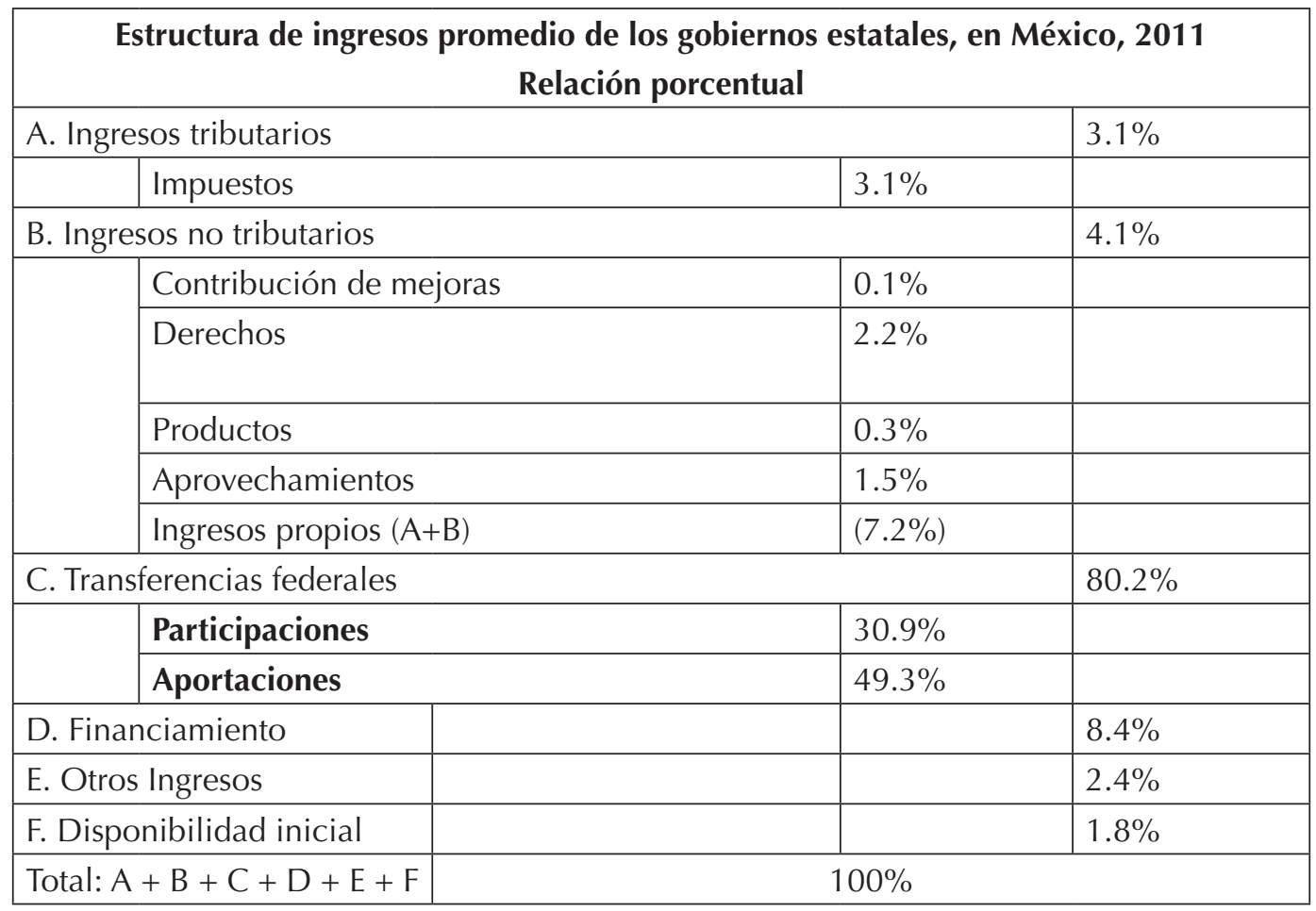

Fuente: Elaboración propia con datos de el ingreso y el gasto público en México. Series de estadísticas sectoriales (INEGI: 2012, p. 140-150).

\section{RELACIÓN DE LAS TRANSFERENCIAS FEDERALES Y ENDEUDAMIENTO PÚBLICO DE ESTADOS Y MUNICIPIOS}

La Ley de Coordinación Fiscal, contempla que las transferencias federales pueden usarse como garantía con las instituciones de crédito para la contratación de deuda pública de estados y municipios en México. El artículo 9 se ésta ley señala:

\footnotetext{
"Las participaciones que correspondan a las Entidades y Municipios son inembargables; no pueden afectarse a fines específicos, ni estar sujetas a retención, salvo para el pago de obligaciones contraídas por las Entidades o Municipios con autorización de las legislaturas locales (el subrayado es mío)"
}

De tal forma que las transferencias federales vía las participaciones, pueden usarse como garantía de deuda, mermando con ello los ingresos futuros de los estados y muni- 
cipios. Esto es sumamente grave si recordamos que los ingresos de Estados y municipios dependen en promedio del 80\% de las transferencias federales.

Actualmente las participaciones son la principal garantía que ofrecen los estados y municipios en la contratación de deuda, éstas representan en promedio más del $80 \%$ de aval de la deuda total, legalmente esta acción es permitida por el artículo 9 de la Ley de Coordinación Fiscal (LCF). El debate parlamentario actual plantea la necesidad de poner un límite porcentual a este aval.

Al quedar las participaciones como garantía, el Estado descuenta de la transferencia de los montos de las obligaciones contraídas, es decir, que a las transferencias financieras, por participaciones que envía la Secretaria de Hacienda y Crédito Público (SHyCP) a las haciendas locales de los estados les resta los compromisos por deuda que éstos previamente hayan contratado.

En los informes de la Secretaria de Hacienda y Crédito Público, sobre las obligaciones financieras de entidades federativas y municipios, se observa que además de las participaciones, que contempla el artículo 9 de la Ley de Coordinación Fiscal, los estados y municipios también pueden dejar como garantía de deuda las aportaciones del Fondo de Aportaciones para la Infraestructura Social (FAIS) y el Fondo de Aportaciones para el Fortalecimiento de las Entidades Federativas (FAFEF). Aunque ambos fondos representan menos del $2 \%$ como garantía de deuda.

\subsection{REGISTRO DE DEUDA PÚBLICA ESTATAL}

El reglamento de registro de deuda que contempla la Ley de Coordinación Fiscal, fue aprobado en 2001 por el ejecutivo federal (Vicente Fox, 2000-2006), se denomina: "Reglamento del artículo 9 de la Ley de Coordinación Fiscal en Materia de Registro de Obligaciones y empréstitos de entidades Federativas y Municipios", establece, entre otros, lo siguiente: "Corresponde a las entidades y municipios efectuar los pagos de las obligaciones con afectación de sus participaciones (subrayado mío), de acuerdo con los mecanismos y sistemas de registro establecidos en sus leyes estatales de deuda"

El reglamento tiene por objeto establecer requisitos para la inscripción en el registro, de las obligaciones contraídas por los Estados, el Distrito Federal o los municipios, con afectación de sus participaciones en ingresos federales.

Se señala que la inscripción de deuda en este registro es independiente de aquel que se realiza en el Registro único de obligaciones y empréstitos de la entidad solicitante. De modo que la deuda pública que tienen los estados en el "Registro de Obligaciones y empréstitos de entidades Federativas y Municipios del Reglamento del artículo 9 de la Ley de Coordinación Fiscal" puede no reflejar el total de la deuda que éstos han contraído, por ello en las reformas que están en proceso en el Congreso de la Unión, se plantea un registro único y estricto de la deuda pública.

Entre los requisitos más importantes para el registro de deuda, que aun contempla la legislación vigente, son: que la legislatura local haya autorizado previamente la obligación afectando las participaciones en los ingresos federales, que se publiquen en un diario de circulación local y en uno nacional, que sea en moneda nacional, que se con- 
trate con la federación o con instituciones de crédito que operen en territorio nacional. Para el caso del DF, además de los requisitos solicitados deberá cumplir las disposiciones de la Ley General de Deuda Pública.

Ni en la Ley de Coordinación Fiscal ni en el Reglamento del artículo 9 de la Ley de Coordinación Fiscal en Materia de Registro de Obligaciones y Empréstitos de Entidades Federativas y Municipios, se establecen límites a los montos del endeudamiento con respecto de las participaciones y de los fondos de aportaciones que fungen como garantes de endeudamiento, esta decisión se contempla como una atribución de las soberanías estatales, establecida en sus respectivas leyes de Deuda Pública.

Es aquí donde se plantea el debate: ¿Si México tiene un sistema federalista, es decir, los estados y municipios tienen autonomía política, por qué el gobierno federal tiene que disciplinarlos en materia de deuda? Este interrogante da para el desarrollo de varios trabajos, pero para acercarnos un poco a su respuesta, y con el riesgo académico que implica, podríamos decir, que es porque no tienen autonomía financiera ni potestades fiscales, que les permita generar los recursos que cada uno de ellos requiere. Ello nos llevaría a la siguiente pregunta: ¿todos los estados y municipios tienen la capacidad económica e institucional para generar los recursos públicos que cada uno de ellos requiere? Acercarse a las respuesta de estos interrogantes es sumamente desafiante, sin embargo, para efectos de este trabajo, plantearemos que es necesario que los estados y municipios incrementen sus ingresos propios (el cómo, es lo que se tiene que debatir), para evitar su dependencia financiera y endeudamiento público.

La falta de establecimiento de límites, genera que el gobierno estatal o municipal en turno sin mayor problema pueda comprometer en más del 100\% sus participaciones como garante de la deuda pública, como es el caso de Coahuila (2008-2011), y afectar severamente las finanzas públicas de los estados y municipios (SHyCP, 2012).

\section{ENDEUDAMIENTO PÚBLICO DE ESTADOS Y MUNICIPIOS}

En este cuadro se aprecia que la deuda con respecto de los ingresos totales garantizables, es decir, de los ingresos que podrán disponer los estados y municipios, representó en 2007 el 41\% y en 2012 el 65.1\%; en 6 años se incrementó 23.7 puntos porcentuales. De modo que la deuda para los estados y municipios tuvo en promedio cada vez un mayor peso en cada uno de los años del gobierno de Felipe Calderón (2006-2012), esto se aprecia claramente en el cuadro 1 en la tercera columna.

En 2006 al inicio del segundo sexenio del PAN, la deuda en relación con las participaciones, representaba el 48.7\%, pero a finales del 2012 aumentó a 86.1\%, un incremento de 37.4 puntos porcentuales, peligrosamente alto. Esto implica que en promedio en 2006 la mitad del monto de las participaciones de estados y municipios equivalía al monto de la deuda y en 2012 rebasó el 85\%.

En el cuadro 1 observamos que la deuda de los estados y municipios de 2001 a 2008, osciló entre 1.5 a 1.7\% del Producto Interno Bruto Estatal (PIBE), pero en 2012 la deuda en relación con el PIBE pasó a casi 3\%. La deuda de estados y municipios en cuatro años, de 2009 a 2012, se duplicó. En el gráfico siguiente se puede apreciar más claramente dicho incremento. 
Tabela 1. Obligaciones financieras de Entidades Federativas y municipios.* Saldos a diciembre de cada año (Millones de pesos y relación porcentual)

\begin{tabular}{|c|c|c|c|c|}
\hline Año & $\begin{array}{l}\text { Saldo total de } \\
\text { las obligaciones } \\
\text { financieras de } \\
\text { los estados y } \\
\text { municipios }\end{array}$ & $\begin{array}{l}\text { Porcentaje con } \\
\text { respecto de los } \\
\text { ingresos totales } \\
\text { garantizables** }\end{array}$ & $\begin{array}{l}\text { Porcentaje con } \\
\text { respecto de las } \\
\text { participaciones }\end{array}$ & $\begin{array}{l}\text { Porcentaje con } \\
\text { respecto del } \\
\text { Producto Interno } \\
\text { Bruto Estatal } \\
\text { (Pibe) }\end{array}$ \\
\hline 1994 & $26,728.5$ & nd & 64.5 & 1.6 \\
\hline 2001 & $99,062.8$ & nd & 50.3 & 1.5 \\
\hline 2002 & $113,702.1$ & nd & 52.9 & 1.7 \\
\hline 2003 & $123,278.2$ & nd & 54.7 & 1.8 \\
\hline 2004 & $130,719.5$ & nd & 54.5 & 1.7 \\
\hline 2005 & $143,193.8$ & nd & 51.3 & 1.7 \\
\hline 2006 & $160,093.5$ & nd & 48.7 & 1.6 \\
\hline 2007 & $186,470.0$ & 41.1 & 56.1 & 1.7 \\
\hline 2008 & $203,070.2$ & 42.7 & 50.7 & 1.7 \\
\hline 2009 & $252,153.5$ & 44.2 & 59.9 & 2.2 \\
\hline 2010 & $314,664.5$ & 56.1 & 72.0 & 2.5 \\
\hline 2011 & $390,777.5$ & 61.4 & 79.2 & 2.9 \\
\hline 2012 & $434,761.2$ & 65.1 & 86.1 & 2.9 \\
\hline
\end{tabular}

Elaboración propia con datos de "Obligaciones financieras de entidades federativas y municipios. Saldos a diciembre de cada año" (SHyCP, 2012).

* Estos datos fueron proporcionados por las entidades federativas a la Secretaria de Hacienda y Crédito Público (SHyCP).

** Incluye las participaciones en ingresos federales (ramo 28), los incentivos fiscales, 25\% del Fondo de Aportaciones para la Infraestructura Social (FAIS), 25\% del Fondo de Aportaciones para el Fortalecimiento de las Entidades Federativas (FAFEE) y los ingresos propios de las entidades federativas, no incluye los ingresos propios de los municipios.

\subsection{ESTADOS CON LOS MAYORES SALDOS DE ENDEUDAMIENTO}

En el cuadro 2 se aprecia a los estados más endeudados del país: Distrito Federal, Nuevo León, Veracruz, Estado de México, Coahuila. El Distrito Federal (o Ciudad de México) es el más endeudado, en 2012 concentró el 13.5\% de la deuda total de los estados, le sigue Nuevo León con el 10.8\%, el tercero el Estado de México 9.1\%, el cuarto Coahuila con el 8.3\%, y el quinto más endeudado es Veracruz con el 9.2\%. Estos cinco estados concentran el 50.9\%, de la deuda total de los Estados y municipios en 2012, pero al mismo tiempo aportan el 42\% del Producto Interno Bruto (PIB) nacional, además son, 
con excepción de Coahuila, los más poblados, concentran 39.1 millones de habitantes, es decir, poco más de una tercera parte de la población total del país (INEGI, 2012).

Los estados menos endeudados son Tlaxcala (0.01), Campeche (0.3), Querétaro (0.5), Baja California Sur (0.5\%), Yucatán (0.6) y Colima (0.6), éstos apenas sumaron en 2011, el 2.5\% de la deuda total de Estados y municipios.

Tabela 2. Obligaciones financieras de los cinco estados más endeudados (millones de pesos)

\begin{tabular}{|r|r|r|r|r|r|}
\hline AÑ & \multicolumn{1}{|c|}{$\begin{array}{l}\text { Distrito } \\
\text { Federal }\end{array}$} & Nuevo León & Veracruz & \multicolumn{1}{|c|}{ México } & \multicolumn{1}{|c|}{ Coahuila } \\
\hline 2006 & $44,085.9$ & $16,711.1$ & $5,514.3$ & $31,975.7$ & 420.0 \\
\hline 2007 & $44,079.5$ & $17,346.2$ & $7,074.4$ & $32,316.3$ & 486.9 \\
\hline 2008 & $45,579.6$ & $17,959.9$ & $9,169.7$ & $32,838.6$ & $1,831.9$ \\
\hline 2009 & $47,529.5$ & $27,070.7$ & $9,331.2$ & $33,017.5$ & $1,561.6$ \\
\hline 2010 & $52,578.5$ & $33,971.5$ & $21,499.9$ & $38,249.7$ & $8,267.1$ \\
\hline 2012 & $56,232.2$ & $38,590.5$ & $27,938.1$ & $38,195.9$ & $36,509.6$ \\
\hline
\end{tabular}

Elaboración propia con datos de "Obligaciones financieras de entidades federativas y municipios. Saldos al cierre del año", (SHyCP, 2012)

En el siguiente gráfico podemos apreciar de mejor manera como se ha incrementado la deuda de los estados con los mayores montos en sus pasivos.

El Distrito Federal es el más endeudado, en 2011 su saldo ascendía a \$ 58,773.8 millones de pesos (vid. cuadro 2) este monto representó el 2.2\% de su Producto Interno Bruto Estatal (PIBE), dada su capacidad de desarrollo y su aportación al PIB nacional (17\%), realmente su deuda es manejable, además podemos observar en el gráfico 2, el ritmo de su endeudamiento no es tan abrupto. Este endeudamiento representa el $40 \%$ de sus ingresos totales en 2011, incluyendo las transferencias federales.

El segundo estado con un mayor saldo de deuda pública es Nuevo León, con \$ 46,952.9 millones de pesos, en 2012, este monto representó el 4.2\% de su PIBE, y aporta al PIB nacional el 7.3\%. El endeudamiento de Nuevo León en 2011 representó el $53.8 \%$ de sus ingresos totales.

Le sigue Veracruz con un monto de deuda en 2012 de \$ 40,028.9 millones de pesos, esta cantidad representa el 5.8\% de su PIBE, muy por arriba del promedio nacional que es del 2.9\%. La economía de este estado aporta el 5.2\% al PIB nacional. En 2011 su endeudamiento público representó el $28.6 \%$ de sus ingresos totales, incluyendo las transferencias federales. 


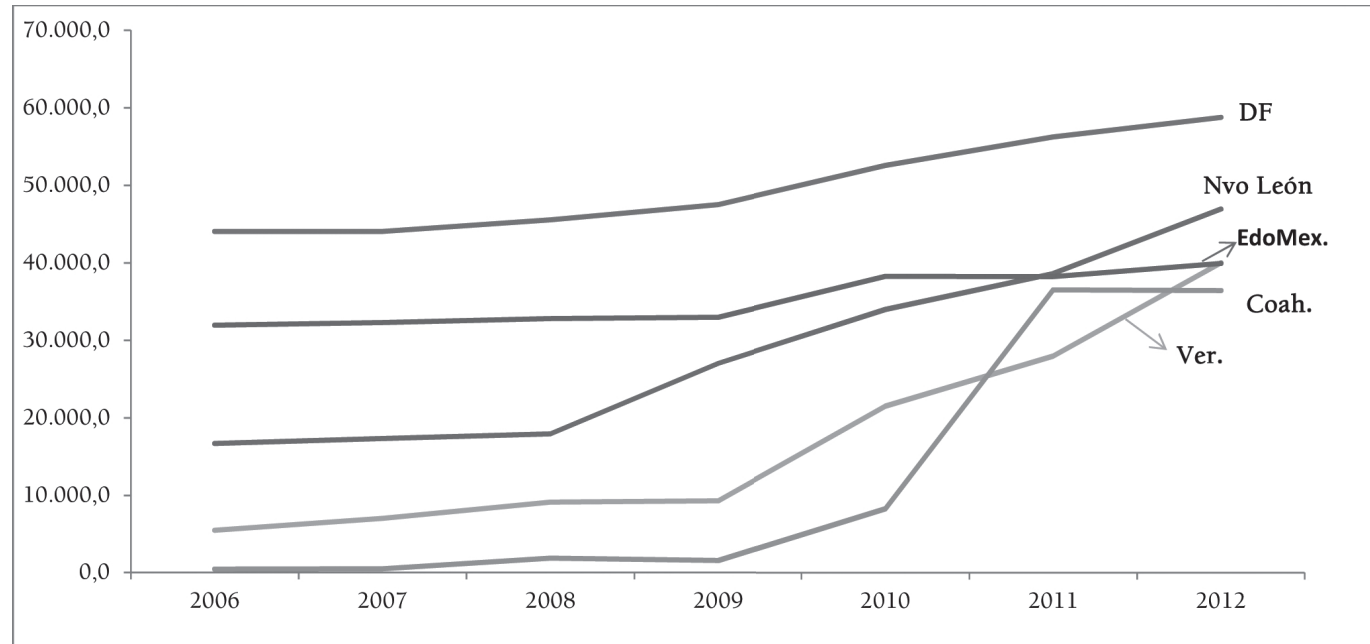

Gráfico 1. Entidades federativas más endeudadas de México (2006-2012) MILLONES DE PESOS

Elaboración propia con datos de "Obligaciones Financieras de entidades federativas y municipios. Saldos al cierre del año" (SHyCP, 2012), "obligaciones de entidades federativas y municipios. Saldo como por ciento del PIB por entidad federativa al cierre de cada año" (SHyCP, 2012).

El cuarto Estado con mayor endeudamiento es el Estado de México, en 2012 debía \$ 39,929.3 millones de pesos, esto representó el 3.0\% de su PIBE. Este estado aporta al PIB nacional el 9.1\%. En 2011 su endeudamiento público representó el 20.6\% de sus ingresos totales.

Y por último Coahuila, como se observa en el cuadro 2, el ritmo de crecimiento de su deuda ha sido muy rápido, en 2006 era de \$ 420 millones de pesos y en 2012 el monto ascendió a \$36,421.7 millones de pesos. En 2011 el monto de su endeudamiento público represento el $55.7 \%$ de sus ingresos totales.

Al inicio de la gestión del gobernador Humberto Moreira, 2005, el saldo de la deuda era de \$ 323.2 millones y al final de su administración, 2011, ascendió a \$ 36,509.6 millones de pesos, es decir, que durante esta administración, la deuda pública del estado se incrementó 112 veces (SHyCP, 2012). El exgobernador fue sometido a investigación judicial, acusado de utilizar documentación apócrifa para la contratación de deuda. En noviembre de 2012, la Procuraduría General de la República (PGR) absolvió a Humberto Moreira del endeudamiento por no contar con las evidencias suficientes para acusarlo formalmente.

El endeudamiento público estatal tiene como garantía tanto a los ingresos propios como a las transferencias federales, principalmente las participaciones. En promedio el $86.1 \%$ de las participaciones están comprometidas como garantía de deuda, pero hay estados que han rebasado con mucho este porcentaje. La relación del endeudamiento de Coahuila con sus participaciones es del 298.5\%, el Distrito Federal con el 105.1\%, Estado de México el 97.8\%, Nuevo León el 208.3\% y Veracruz el $131.2 \%$, éstos además de ser los estados más endeudados son los que tienen una alta relación de su deuda con las participaciones (SHyCP, 2012). 


\subsubsection{PLAZOS DE LA DEUDA PÚBLICA DE LOS ESTADOS}

El plazo de la deuda pública de los estados y municipios se incrementó a nivel nacional casi el doble de tiempo del 2006 al 2012, paso de 8.8 a 15.1 años. Todos los gobiernos se endeudaron por encima de su periodo de gobierno, con la excepción de Tlaxcala.

A continuación mencionaremos los plazos de endeudamiento de los cinco estados con mayores pasivos. El Distrito Federal es el que tiene los plazos más largos pero también han aumentado de manera considerable del 2006 al 2012, en este periodo paso de 9.2 a 22.4 años, tuvo un incremento de 13.2 años, en 2007 el plazo más largo de su deuda fue de 29 años.

Veracruz es el que más ha incrementado los plazos de su deuda, paso de 5.4 años en 2006 a 19.6 años en 2012, tuvo un aumento en este periodo de 14.2 años, está muy por arriba del promedio nacional que es de 15.1 años.

El Estado de México no ha tenido aumentos considerables en los plazos de su deuda pública, en 2006 era de 16.4 años y en 2012 de 18.4, sus plazos solo aumentaron 2 años, sin embargo, se encuentra por encima del promedio nacional.

Nuevo León también incrementó los periodos de su deuda de 2006 a 2012, paso de 10.6 a 14.6 años. Coahuila ha tenido un aumento bastante significativo del aumento del plazo su deuda, paso de 8.8 a 18.9 años en este periodo, es decir, que los plazos de su deuda aumentaron 10.9 años.

Los gobernadores no solo comprometen los ingresos futuros de las transferencias federales, al dejar a las participaciones como garantía de deuda, sino además han incrementado los plazos de sus pasivos, pasando en promedio en 2006 de 8.8 años a 15.1 años para 2012, aunque en algunos casos, como Veracruz han incrementado los plazos de endeudamiento hasta 4 veces. Los gobernadores que contraen deuda a largo plazo dejan endeudadas hasta tres administraciones futuras.

Tabela 3. Plazo promedio de vencimiento ponderado por el monto de las obligaciones de las cinco entidades federativas* más endeudadas, plazo promedio en años, al cierre de cada año, 2006-2012

\begin{tabular}{|l|c|c|c|c|c|c|c|}
\hline \multicolumn{1}{|c|}{ ESTADOS } & 2006 & 2007 & 2008 & 2009 & 2010 & 2011 & 2012 \\
\hline & Años & Años & Años & Años & Años & Años & Años \\
\hline Coahuila & 8.8 & 7.1 & 11.9 & 11.9 & 12.5 & 18.3 & 18.9 \\
\hline Distrito Federal & 9.2 & 29 & 27.5 & 26.1 & 23.9 & 19.3 & 22 \\
\hline México & 16.4 & 14.3 & 21.3 & 20.3 & 19.4 & 16.7 & 18.4 \\
\hline Nuevo León & 10.6 & 17.2 & 16.1 & 18.5 & 13.9 & 12.2 & 13.4 \\
\hline Veracruz & 5.4 & 26.7 & 25.3 & 24 & 16.4 & 18.6 & 20.6 \\
\hline Promedio nacional de 32 entidades & 8.8 & 12.6 & 13.5 & 13.9 & 13.6 & 13.8 & 15.1 \\
\hline
\end{tabular}

Elaboración propia con datos de "Obligaciones Financieras de Entidades Federativas y Municipios. Plazo promedio de vencimiento ponderado por el monto de las obligaciones por Entidad Federativa. Al cierre de cada año" (SHyCP, 2012).

*Es importante señalar que el Distrito Federal en términos administrativos no es considerada, una entidad federativa, debido a que no tiene plena autonomía política, se encuentra pendiente su reforma política. 


\subsubsection{ACREEDORES DE LOS ESTADOS Y MUNICIPIOS EN MÉXICO}

A finales de 2012 a nivel nacional los estados y municipios se encontraban mayormente endeudados con la banca comercial, 61.4\%, en México el 90\% de la banca privada es extranjera. El 20.5\% de los pasivos de los estados están contratados con la banca de desarrollo, el 15.1\% con emisiones bursátiles. Sólo 9 de las 32 entidades emiten deuda bursátil.

De los cinco estados con mayores pasivos, el Distrito Federal tiene su deuda bastante diversificada, con comparación con los datos nacionales, el 30.3\% con la banca comercial, el 35\% con la de desarrollo, el $22.7 \%$ es bursátil y el 12\% con fideicomisos.

Tabela 4. Obligaciones financieras de entidades y municipios en México (Millones de pesos y porcentajes con respecto a la deuda total de cada Estado: Saldos al 31.12.2012)

\begin{tabular}{|c|c|c|c|c|c|c|c|c|c|c|}
\hline \multirow{2}{*}{ Estados } & \multicolumn{2}{|c|}{ Distrito Federal } & \multicolumn{2}{|c|}{ Nuevo León } & \multicolumn{2}{|c|}{ Veracruz } & \multicolumn{2}{|c|}{ México } & \multicolumn{2}{|c|}{ Coahuila } \\
\hline & monto & $\%$ & monto & $\%$ & monto & $\%$ & monto & $\%$ & monto & $\%$ \\
\hline $\begin{array}{l}\text { Banca } \\
\text { comercial }\end{array}$ & $17,833.5$ & 30.3 & $28,193.6$ & 60 & $19,433.3$ & 48.5 & $34,366.1$ & 86.2 & $35,118.1$ & 96.4 \\
\hline $\begin{array}{l}\text { Banca de } \\
\text { desarrollo }\end{array}$ & $20,576.8$ & 35.0 & $9,947.2$ & 21.2 & $6,779.3$ & 17.0 & $1,097.3$ & 2.6 & $1,268.6$ & 3.5 \\
\hline $\begin{array}{l}\text { Emisiones } \\
\text { bursátiles }\end{array}$ & $13,363.5$ & 22.7 & $8,360.4$ & 17.8 & $13,710.0$ & 34.3 & $3,974.2$ & 10.0 & - & - \\
\hline Fideicomisos & $7,000.0$ & 12 & - & - & - & - & - & - & - & 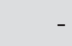 \\
\hline Otros & & - & 451.7 & 1.0 & 112.4 & 0.2 & 491.7 & 1.2 & 34.9 & 0.1 \\
\hline Total & $58,773.8$ & 100 & $46,952.9$ & 100 & $40,028.9$ & 100 & $39,929.3$ & 100 & $36,421.7$ & 100 \\
\hline
\end{tabular}

Fuente: elaboración propia con datos de Obligaciones de entidades federativas y municipios con la banca comercial, banca de desarrollo, emisiones bursátiles, fideicomisos y otros (SHyCP, 2012).

El principal acreedor del estado de Nuevo León es la banca comercial con un $60 \%$ del total de sus pasivos, el $21.2 \%$ los tiene contratados con la banca de desarrollo y el $17.8 \%$ con emisiones bursátiles.

El estado de Veracruz tiene contratados casi la mitad de sus pasivos con la banca comercial, $48.5 \%$, el $17 \%$ con la banca de desarrollo y casi una tercera parte de sus pasivos, $34.3 \%$, son emisiones bursátiles garantizadas principalmente con participaciones.

El Estado de México tiene la mayoría de sus pasivos contratados con la banca comercial, el 86.2\%, el 2.6\% con la banca de desarrollo y el 10\% en emisiones bursátiles.

Coahuila tiene casi todos sus pasivos contratados con la banca comercial, el $96.4 \%$ y el resto con la banca de desarrollo.

La mayoría de los estados han aumentado la contratación de su deuda pública con la banca ya que ésta queda garantizada con las participaciones y con los ingresos propios, 
este tipo de garantías es muy atractivo para la banca comercial. Uno de los debates es que se deben implementar límites a la banca comercial para que tenga máximo de préstamo a los estados y municipios en México.

El costo promedio ponderado de la deuda pública estatal se ubicaba en 2012 a una tasa de interés nominal anual del $6.5 \%$ a nivel nacional. Para Coahuila tenía un costo ponderado de 7.7\%, para el Distrito Federal del 6.6\%, Estado de México 6.2\%, Nuevo León $6.2 \%$ y Veracruz de 5.3\%. (SHyCP, 2012).

\subsection{ESTADOS CON UN INCREMENTO ACELERADO DE SU DEUDA PÚBLICA}

El cuadro 5 es muy similar al cuadro 2 debido a que Nuevo León, Veracruz y Coahuila, además de ser los estados con los mayores saldos de pasivos, también son los que han tenido un ritmo acelerado de endeudamiento.

El Distrito Federal a pesar de ser el más endeudado de todos los estados, observa desde 2006 un endeudamiento entre 2.2 y 2.5 de su PIBE, de modo que éste no ha sido abrupto. Lo mismo sucede con el Estado de México, el cuarto más endeudado, su endeudamiento ha oscilado entre 3.0 y $3.6 \%$ de su PIBE.

El caso más escandaloso de incremento acelerado de su deuda es Coahuila, en 2006 el saldo de su deuda representó el 0.1\% de su PIBE, en 2009 el 0.5\%, pero en 2011, fue de $8.5 \%$ de su PIBE, cuando este estado apenas aporta el 3.3\% al PIB nacional.

Los dos estados, que no se ubican dentro de los cinco más endeudados, pero si están dentro de los cinco que han tenido un incremento rápido de su deuda son Jalisco y Chihuahua.

Jalisco de 2006 a 2012, incremento tres veces su deuda pasó en el mismo periodo de $1.4 \%$ a $2.7 \%$ de su PIBE. En Chihuahua también se incrementó tres veces el monto de sus pasivos, paso en el mismo periodo de 2.1 a $4.9 \%$ de su PIBE.

Tabela 5. Principales estados con incremento acelerado de la deuda 2006-2012 (Millones de Pesos)

\begin{tabular}{|r|r|r|r|r|r|}
\hline AÑO & COAHUILA & VERACRUZ & NUEVO LFÓN & JALISCO & CHIHUAHUA \\
\hline 2006 & 420.0 & $5,514.3$ & $16,711.1$ & $8,830.8$ & $6,896.7$ \\
\hline 2007 & 486.9 & $7,074.4$ & $17,346.2$ & $8,480.4$ & $6,623.3$ \\
\hline 2008 & $1,831.9$ & $9,169.7$ & $17,959.9$ & $12,309.9$ & $6,300.6$ \\
\hline 2009 & $1,561.6$ & $9,331.2$ & $27,070.7$ & $20,163.4$ & $13,183.0$ \\
\hline 2010 & $8,267.1$ & $21,499.9$ & $33,971.5$ & $22,122.9$ & $12,547.0$ \\
\hline 2011 & $36,509.6$ & $27,938.1$ & $38,590.5$ & $24,309.0$ & $17,318.6$ \\
\hline
\end{tabular}

Elaboración propia con datos de "Obligaciones Financieras de entidades federativas y municipios. Saldos al cierre del año", (SHyCP, 2012). 
En el siguiente gráfico se puede observar el ritmo de endeudamiento de Coahuila, de 2010 a 2011 se dispara abruptamente. Dejándole a las siguientes administraciones (la siguiente inmediata 2011-2017 es la de su hermano Rubén Moreira) serios problemas financieros, debido a que la contratación de pasivos fue por 20 años (SHyCP, 2012). Chihuahua y Veracruz, observan en el gráfico anterior un ritmo acelerado de endeudamiento muy similar.

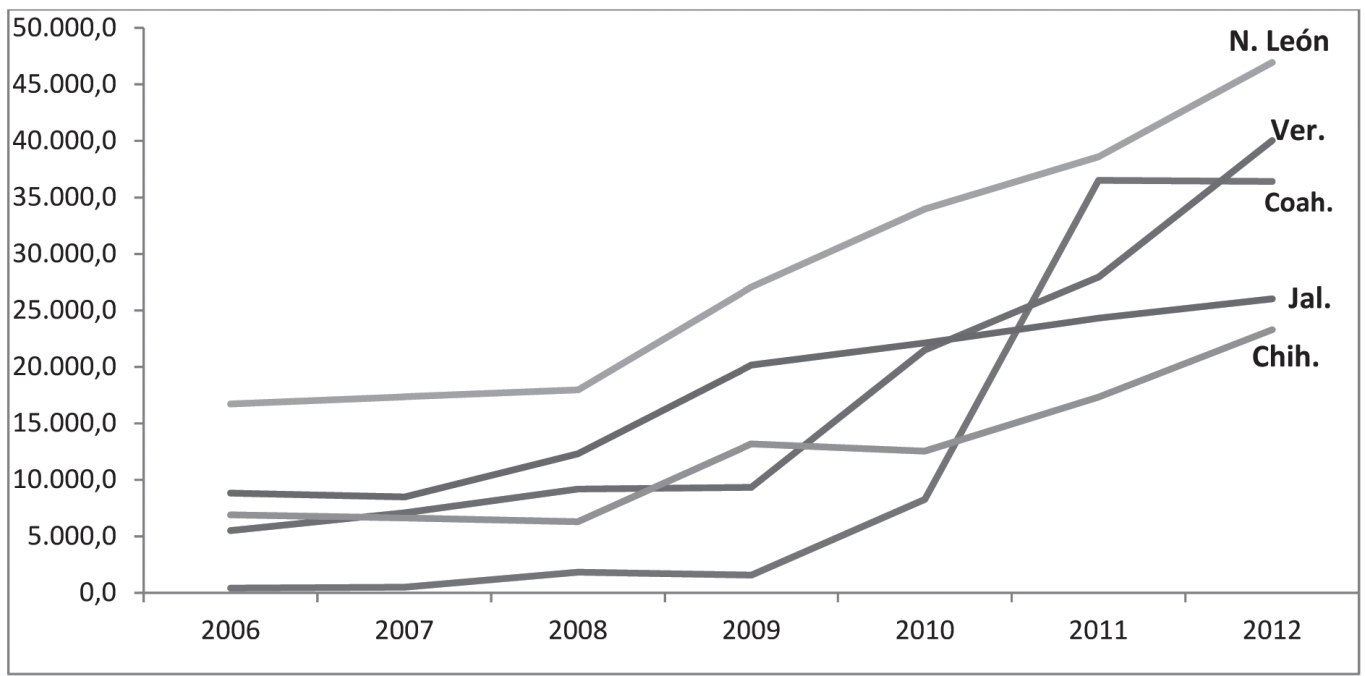

Gráfico 2. Estados con un INCREMENTO ACEleRAdo De Su DeUdA, 2006-2012 (MiLLONES DE PESOS)

Elaboración propia con datos de "Obligaciones Financieras de entidades federativas y municipios. Saldos al cierre del año" (SHyCP, 2012).

\section{CONCLUSIÓN}

El Sistema Nacional de Coordinación Fiscal, además de establecer las relaciones financieras entre la federación y los estados y municipios, también permite a los estados y municipios la posibilidad de que se endeuden dejando como garantía las transferencias federales futuras, con ello se facilita su endeudamiento.

Los estados tienen pocas fuentes de recaudación fiscal, al entrar al SNCF, renunciaron a sus potestades tributarias a cambio de coparticipar de la recaudación de impuestos del gobierno federal, esta situación los ha hecho sumamente dependientes de las transferencias federales. Los estados generan muy pocos recursos propios, en promedio menos del 10\% de sus ingresos totales. Y ven como alternativa fácil endeudarse y comprometer los recursos financieros futuros de la jurisdicción.

Además al no existir limitaciones al endeudamiento, el problema se agrava. La reforma que se discute en el congreso nacional y que también deberá ser discutida y aprobada en los congresos de los estados, se buscará regular y limitar este endeudamiento. 
En promedio la deuda de los estados y municipios mexicanos representa el 3\% de su Producto Interno Bruto Estatal, visto así pareciera que no es un problema grave, pero sí lo es, comprometen ingresos futuros (participaciones y aportaciones) y con ello ponen en riesgo la provisión de bienes públicos locales, ya que en promedio dependen de las transferencias federales en un $80 \%$ en promedio.

Los estados más endeudados son los que concentran más población y al mismo tiempo tienen una gran presión para proveer bienes públicos, y aunque son los que más aportan al Producto Interno Bruto nacional (excepto Coahuila) y por tanto la capacidad de generar recursos propios es alta, en realidad generan pocos recursos propios (excepto Distrito Federal).

Otro problema que se tiene es la falta de transparencia, los estados no reportan en que se gastan los recursos que obtienen por financiamiento de deuda, sobre este asunto existe una gran opacidad y también se debate en la reforma que está en el Congreso de la Unión.

\section{BIBLIOGRAFÍA}

ASTUDILLO, Marcela Moya. El federalismo y la coordinación impositiva en México. México: Instituto de Investigaciones Económicas, 1999.

Finanzas locales. In: coord. CONCHAS, Enrique Arriaga. Finanzas públicas de México. 2. ed. México: IPN, 2001.

AYALA, Espino José. Economía del sector público mexicano. México: Esfinge, 2005.

BAILEY, Stephen. Public Sector Economics - Theory, policy and practice. 3. ed. Londres: Mac Millan, 1995.

CALDERÓN RODRÍGUEZ, José María. El federalismo fiscal y las relaciones intergubernamentales en México. 1998. 680 p. Tesis (Doctorado en Economía Política). Facultad de Economía, Universidad Autónoma de México, México DF.

CORDERA, Rolando; LOMELÍ, Leonardo. Coloquio Federalismo fiscal y federalismo social, México. México: UNAM-SEDESOL, 2004.

INSTITUTO NACIONAL DE ESTADÍSTICA, GEOGRAFÍA Y INFORMÁTICA. Censo de población $y$ vivienda, 2010.

El ingreso y el gasto público en México. Series de estadísticas sectoriales. México, Instituto Nacional de Estadística, Geografía e Informática, 2011.

El ingreso y el gasto público en México. Series de estadísticas sectoriales. México, Instituto Nacional de Estadística, Geografía e Informática, 2013, p. 140-150.

MÉXICO. Ley de Coordinación Fiscal, Cámara de Diputados. Diario Oficial de la Federación. 12 de diciembre del 2011.

MUSGRAVE, Richard. Teoría de la Hacienda Pública. Madrid: Mac Graw Hill, 1969.

OATES, Wallace. Federalismo Fiscal. Madrid: Instituto de Estudios de Administración Local, 1977.

PÉREZ TORRES, Javier; GONZÁLEZ HERNANDEZ, Ignacio. La descentralización fiscal en México. Santiago: CEPAL/GTZ, Serie Política Fiscal, n. 106, 1997.

SANDOVAL, Antonio. Concentrado en 3 instituciones el 63\% de los créditos a Estados y municipios. Este tipo de préstamos representa el 35.73\% del capital contable del sistema bancario nacional. El Financiero, México, 13 de abril 2012. Sección mercados, p. 1 A. 
SECRETARÍA DE HACIENDA Y CRÉDITO PÚBLICO. Informe. Obligaciones Financieras de Entidades Federativas y Municipios. Costo promedio ponderado por Entidad Federativa (tasa de interés nominal anual), del 2001 al 2012. Disponible en: <http://www.hacienda.gob.mx/Estados/Deuda_Publica_EFM/2012/Paginas/4toTrimestre.aspx >.

Informe. Obligaciones Financieras de Entidades Federativas y Municipios garantizada con participaciones e ingresos propios, con la banca comercial, de desarrollo y en emisiones bursátile, 2011. Disponible en: <http://www.hacienda.gob.mx/Estados/Deuda_Publica_EFM/2011/ Paginas/lerTrimestre.aspx $>$.

Informe. Obligaciones Financieras de Entidades Federativas y Municipios respecto a los ingresos totales, las participaciones y el PIB, Elaborado por la Unidad de Coordinación con Entidades Federativas, 2011. Disponible en: <http://www.hacienda.gob.mx/Estados/Deuda_Publica_EFM/2011/ Paginas/lerTrimestre.aspx $>$.

Informe. Obligaciones Financieras de Entidades Federativas y Municipios. Saldos al cierre del año, 2012. Disponible en: <http://www.hacienda.gob.mx/Estados/Deuda_Publica_EFM/2012/ Paginas/4toTrimestre.aspx> Consultada el 16 de agosto del 2013.

. Informe. Obligaciones Financieras de Entidades Federativas y Municipios. Saldos a diciembre de cada año, 2012. Disponible en:<http://www.hacienda.gob.mx/Estados/Deuda_Publica_EFM/2012/ Paginas/4toTrimestre.aspx> Consultada el 16 de agosto del 2013.

Informe. Obligaciones Financieras de Entidades Federativas y Municipios. Plazo promedio de vencimineto ponderado por el monto de las obligaciones por Entidad Federativa. Al cierre de cada año, 2012. Disponible en: <http://www.hacienda.gob.mx/Estados/Deuda_Publica_EFM/2012/ Paginas/4toTrimestre.aspx> Consultada el 16 de agosto del 2013.

Informe. Obligaciones Financieras de Entidades Federativas y Municipios. Relación entre las obligaciones financieras y las participaciones en ingresos federales por Entidad Federtiva. Al cierre de cada año, 2012. Disponible en:<http://www.hacienda.gob.mx/Estados/Deuda_Publica_EFM/2012/ Paginas/4toTrimestre.aspx> Consultada el 16 de agosto del 2013.

Informe. Obligaciones Financieras de Entidades Federativas y Municipios. Saldo como por ciento del PIB por Entidad Federativa al cierre de cada año, 2012. Disponible en: <http://www.hacienda.gob. mx/Estados/Deuda_Publica_EFM/2012/Paginas/4toTrimestre.aspx >.

. Informe. Obligaciones de entidades federativas y municipios con la banca comercial, banca de desarrollo, emisiones bursátiles, fideicomisos y otros, 2012. Disponible en: <http://www.hacienda.gob. mx/Estados/Deuda_Publica_EFM/2012/Paginas/4toTrimestre.aspx>.

Informe. Obligaciones Financieras de Entidades Federativas y Municipios. Relación entre las obligaciones financieras y las participacioens en ingreos federales por entidadfederativa, 2012. Disponible en:<http://www.hacienda.gob.mx/Estados/Deuda_Publica_EFM/2012/Paginas/4toTrimestre.aspx>. TELLO MACIAS, Carlos. Sobre las relaciones fiscales entre la federación y los estados. In Federalismo fiscal. Federalismo social. Coord. Rolando Cordera. México, Ed. UNAM-SEDESOL, 2004, p. 118-138. VICTORIA, Alfredo Carlos Marín. La deuda del sector público en México: una crisis inminente. México: UNAM, 2010. 